\title{
Human Small Cell Lung Cancer Cell Lines Expressing the Proopiomelanocortin Gene Have Aberrant Glucocorticoid Receptor Function
}

\author{
D. W. Ray, A. C. Littlewood, A. J. L. Clark, ` J. R. E. Davis, and A. White \\ Department of Medicine, University of Manchester, Manchester M13 9PT; and *Department of Endocrinology, St. Bartholomew's \\ Hospital, London EC1A $7 B E$, United Kingdom
}

\begin{abstract}
Some human small cell lung carcinomas (SCLC) secrete proopiomelanocortin (POMC) derived peptides, but in contrast to the pituitary, glucocorticoids fail to inhibit this hormone production. We have previously described an in vitro model using human SCLC cell lines that express POMC and are resistant to glucocorticoids. We have now identified the glucocorticoid receptor (GR) in the SCLC cell line COR L24 using a whole cell ligand binding assay $\left(K_{d}=5.7 \mathrm{nM} ; B_{\max }=11 \mathrm{fmol} / \mathrm{million}\right.$ cells ), while another cell line, DMS 79, lacked significant glucocorticoid binding. To analyze GR function both positive (GMCO) and negative (TRE) ${ }_{3}$-tkCAT), glucocorticoid-regulated reporter gene constructs were transfected into COR L24 cells.
\end{abstract}

In the SCLC cell line, neither hydrocortisone nor dexamethasone (500-2,000 $\mathrm{nM}$ ) significantly induced chloralmphenicol acetyltransferase expression from GMCO; in addition, they did not suppress chloramphenicol acetyltransferase expression from (TRE) ( $_{3}$-tkCAT. Similar results were obtained with two other POMC-expressing SCLC cell lines. Expression of wild type GR in COR L24 cells restored glucocorticoid signaling, with marked induction of GMCO reporter gene expression by dexamethasone $(9,100 \pm 910 \% ; n=3)$, and an estimated $\mathrm{EC}_{50}$ of $10 \mathrm{nM}$. This failure of the GR explains the resistance of the POMC gene to glucocorticoid inhibition and may have implications for cell growth in SCLC. (J. Clin. Invest. 1994. 93:16251630.) Key words: glucocorticoids - ectopic hormone syndromes • lung neoplasms $\bullet$ hormone receptors $\bullet$ steroid receptors

\section{Introduction}

Most extrapituitary tumors causing Cushing's syndrome are of lung origin $(1,2)$. The gene encoding the ACTH precursor, proopiomelanocortin (POMC), ${ }^{1}$ is expressed at a low level in normal lung (3), and POMC-derived peptides and mRNA have been detected in most histological types of bronchogenic

Address correspondence to D. W. Ray, MRCP, Department of Medicine, University of Manchester, Stopford Building, Oxford Road, Manchester M13 9PT, United Kingdom.

Received for publication 27 September 1993 and in revised form 30 November 1993.

1. Abbreviations used in this paper: CAT, chloramphenicol acetyltransferase; GR, glucocorticoid receptor; POMC, proopiomelanocortin; tk, thymidine kinase; SCLC, small cell lung carcinoma; TPA, 12-O-tetradecanoylphorbol-13-acetate; TRE, phorbol ester response element.

J. Clin. Invest.

(C) The American Society for Clinical Investigation, Inc. $0021-9738 / 94 / 04 / 1625 / 06 \$ 2.00$

Volume 93, April 1994, 1625-1630 carcinoma, although secretion of peptide products is restricted to tumors with significant neuroendocrine differentiation, usually small cell lung carcinoma (SCLC) (1). In vivo, POMC expression in these extrapituitary tumors is characteristically resistant to glucocorticoid repression (2). This feature is used in the high dose dexamethasone suppression test to distinguish extrapituitary tumors causing ectopic ACTH syndrome from pituitary-dependent Cushing's disease, in which the physiological negative feedback by glucocorticoids on POMC expression is partly preserved.

Many SCLC tumors synthesize and secrete peptide hormones, including POMC-derived peptides, and $50 \%$ of patients with SCLC have elevated cortisol levels presumably as a result of ACTH-like bioactivity (4). We have established an in vitro model using a panel of human SCLC cell lines that express the POMC gene (5). We have previously demonstrated the presence of glucocorticoid receptor (GR) in the SCLC cell line COR L103 using a nuclear steroid binding assay (6), but despite this, POMC gene expression and peptide secretion are highly resistant to glucocorticoid negative feedback (6). Whereas anterior pituitary corticotroph tumor cells in primary culture suppress ACTH peptide production at $25 \mathrm{nM}$ hydrocortisone, the SCLC cell line DMS 79 required 1,000 nM hydrocortisone, and in two other cell lines, COR L103 and COR L24, peptide production was significantly suppressed only at 2,000 nM (7).

There are several potential reasons for the resistance of POMC expression to glucocorticoid negative feedback. There could be a defect in the POMC gene itself, a global abnormality of glucocorticoid signaling, or the presence of a steroid metabolizing enzyme (e.g., $11 \beta$-hydroxysteroid dehydrogenase) preventing effective activation of the GR.

The aim of these studies was to examine glucocorticoid signaling by transfecting SCLC cells with simple, exogenous, glucocorticoid-regulated reporter genes and comparing a range of concentrations of both the physiological glucocorticoid, hydrocortisone, and the synthetic glucocorticoid, dexamethasone.

\section{Methods}

Cell culture. The COR L24 and COR L103 cell lines were derived from patients with pathologically confirmed SCLC and were generously donated by Dr. P. Twentyman (MRC Clinical Oncology and Radiotherapeutics Unit, Cambridge, United Kingdom). DMS 79 cells were derived from a patient with SCLC and were kindly donated by Prof. $O$. Pettengill (Dartmouth Medical School, Hanover NH). The cells were grown as previously described (6), using RPMI 1640 and supplemented with $2.5 \%$ fetal calf serum (Flow Laboratories, Inc., McLean, VA), human transferrin $(10 \mu \mathrm{g} / \mathrm{ml})$, bovine insulin $(5 \mu \mathrm{g} / \mathrm{ml})$, sodium selenite $\left(3 \times 10^{-8} \mathrm{M}\right)$, Hepes buffer $(10 \mathrm{mM})$, glutamine (4 $\mathrm{mM})$, and sodium pyruvate $(1 \mathrm{mM})$. Incubation was at $37^{\circ} \mathrm{C}$ in an atmosphere of $5 \% \mathrm{CO}_{2} . \mathrm{GH}_{3}$ cells were cultured as previously described (8) in Ham's F10 medium supplemented with 10\% horse 
serum and 5\% fetal calf serum. Dexamethasone, hydrocortisone, and 12-O-tetradecanoylphorbol-13-acetate (TPA) were purchased from Sigma Chemical Co. (Poole, United Kingdom).

Plasmids. GMCO was the kind gift of Prof. K. Yamamoto (University of California, San Franscisco, CA), and contains the murine mammary tumor virus positive glucocorticoid response element linked to the chloramphenicol acetyltransferase (CAT) reporter gene, and previous data have confirmed the plasmid to be inducible by dexamethasone (9). (TRE) ${ }_{3}$-tkCAT, consists of three tandem repeats of the phorbol ester response element (TRE), sequence AGCTTAAAGCATGAGTCAGACACCT (10) ligated to the herpes simplex thymidine kinase (tk) promoter in pBL-CAT2 (11). We are very grateful to Dr. Bernard Peer (University of Liege, Liege, Belgium) for kindly providing us with this construct. RS-hGR $\alpha$ contains the full length coding region of the human glucocorticoid receptor under the control of the promoter from the Rous sarcoma virus, and was the kind gift of Dr. R. Evans (Salk Institute for Biological Studies, La Jolla, CA) (12).

Transfection. Cells were washed twice in serum free medium then resuspended with DNA in a 4-mm path length electroporation cuvette (Bio-Rad, Hemel Hempstead, United Kingdom). All cells were electroporated with a $200-\mathrm{V}$ pulse at $1,500 \mu \mathrm{F}$ capacitance (Electropore 2000; SEDD, Liege, Belgium). The transfected pools of cells were resuspended in supplemented medium then divided into treatment and control cultures to ensure similar transfection efficiency between groups (8). Cells transfected with just GMCO $(54 \mu \mathrm{g})$ or (TRE) $)_{3}$-tkCAT ( 9 $\mu \mathrm{g}$ ) were harvested after $24 \mathrm{~h}$ culture, washed twice in sterile phosphate buffered saline and pelleted at $400 \mathrm{~g}$. In the cotransfection studies with RS-hGR $\alpha(6 \mu \mathrm{g})$, cells were cultured for $48 \mathrm{~h}$ before harvest.

$C A T$ assay. This was performed as previously described (13). Briefly, cells were resuspended in hypotonic Tris $(0.25 \mathrm{M}, \mathrm{pH} 7.6)$ and lysed by three cycles of rapid freezing and thawing. Endogenous acetylase activity was reduced by incubation of cell lysate at $65^{\circ} \mathrm{C}$ for $6 \mathrm{~min}$. All the lysate was used in each incubation with $\left[{ }^{14} \mathrm{C}\right]$ chloramphenicol (Amersham International, Amersham, United Kingdom), acetyl CoA (Sigma Chemical Co.), and $1 \mathrm{M}$ Tris ( $\mathrm{pH} \mathrm{7.8)} \mathrm{buffer} \mathrm{for} 2 \mathrm{~h}$. The reaction was terminated by extracting the chloramphenicol with ethyl acetate. Chloramphenicol and acetylated products were separated by thin layer chromatography (methanol 5\%/chloroform 95\%), and visualized by autoradiography. To quantitate acetylation the thin layer chromatography plates were cut and measured in a beta scintillation counter.

Glucocorticoid receptor studies. Cells in late log phase growth were harvested and resuspended in serum free medium for $48 \mathrm{~h}$. The cells were then washed once in serum free medium and resuspended in serum-free medium to a final density of $\sim 1 \times 10^{6} \mathrm{cells} / \mathrm{ml}$ in $400 \mu \mathrm{l}$. $50-\mu l$ aliquots of serially diluted $\left[{ }^{3} \mathrm{H}\right]$ dexamethasone $\left(1,2,4,6,7-{ }^{3} \mathrm{H}\right.$ dexamethasone, specific activity $=89 \mathrm{Ci} / \mathrm{mmol}$, Amersham International) were added to the cells to give final concentrations of between 1 and $50 \mathrm{nM}$. Parallel incubations with a 200 -fold molar excess of unlabeled dexamethasone were performed to estimate nonspecific binding. After a 1-h incubation at $37^{\circ} \mathrm{C}$, cells were harvested, washed twice in ice-cold PBS, and lysed with $10 \%$ glycerol and $1 \%$ Triton X-100 in 25 $\mathrm{mM}$ Hepes. $4 \mathrm{ml}$ scintillant was added to the cell lysate, and counted in a $\beta$ scintillation counter. Specifically bound dexamethasone is expressed as fmol/million cells. Data were analyzed using the Simfit package (W. Bardsley, University of Manchester, Manchester, United Kingdom) running on an IBM 286 PC.

\section{Results}

Glucocorticoid receptors were identified in SCLC cell line, COR L24, using a whole cell ligand binding assay. The receptor binds dexamethasone with a $K_{\mathrm{d}}$ of $5.7 \mathrm{nM}$ (mean of triplicate determinations, representative of assays performed on five separate occasions), and a $B_{\max }$ of $11.1 \mathrm{fmol} /$ million cells. The mouse pituitary AtT 20 corticotroph cell line, bound dexamethasone under the same conditions with a $K_{\mathrm{d}}$ of $5.2 \mathrm{nM}$ and a
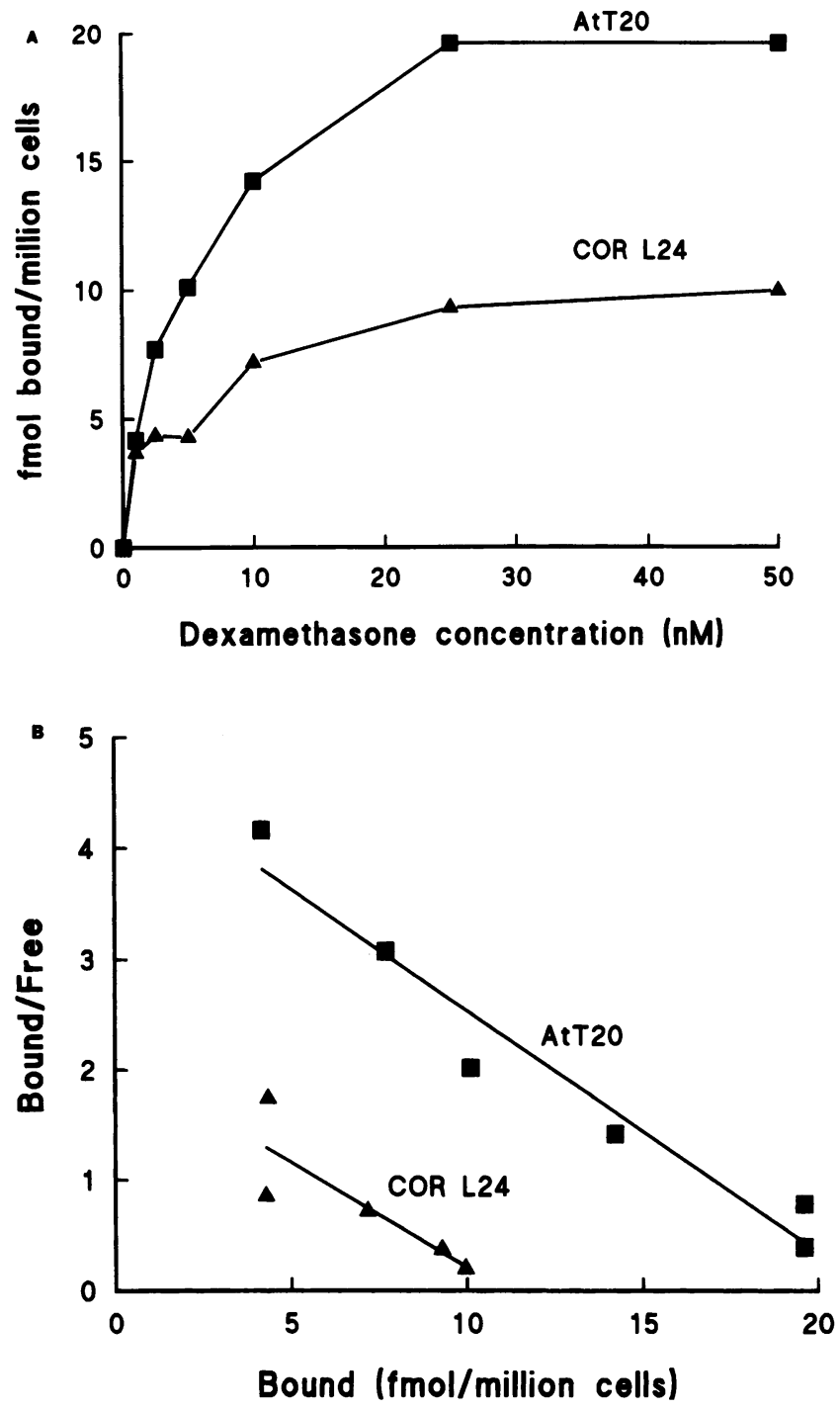

Figure 1. (A) Binding of dexamethasone to AtT20 and COR L24 cells, results are mean of triplicate determinations, representative of assays performed on five separate occasions. $\left[{ }^{3} \mathrm{H}\right]$ dexamethasone was incubated with cells for $1 \mathrm{~h}$. Nonspecific binding was calculated by coincubation with unlabeled dexamethasone in 200 -fold molar excess. $(B)$ Scatchard transformation of data in $(A)$. The affinity of dexamethasone binding was similar between COR L24 $\left(K_{d}=5.7 \mathrm{nM}\right)$ and AtT 20 cells $\left(K_{d}=5.2 \mathrm{nM}\right)$, but there was a consistent difference in the receptor concentration (AtT20 $B_{\max }=22.3 \mathrm{fmol} / \mathrm{million}$ cells, COR L24 $B_{\max }=11.1 \mathrm{fmol} /$ million cells $)$.

$B_{\max } 22.3 \mathrm{fmol} / \mathrm{million}$ viable cells (Fig. 1). Under the same assay conditions, we were unable to consistently demonstrate high affinity dexamethasone binding in DMS 79 cells. The relatively minor difference in receptor concentration between COR L24 and AtT20 cells contrasted with the severely glucocorticoid resistant phenotype of the COR L24 cells, and so a series of functional studies were undertaken.

Rat pituitary $\mathrm{GH}_{3}$ cells, which are known to be glucocorticoid responsive, were transfected with the glucocorticoid-inducible GMCO reporter construct and displayed appropriate glucocorticoid activation of CAT expression with $500 \mathrm{nM}$ dexamethasone increasing expression to $810 \pm 75 \%$ (SEM) of control levels $(n=3)$. In contrast, parallel studies in COR L24 


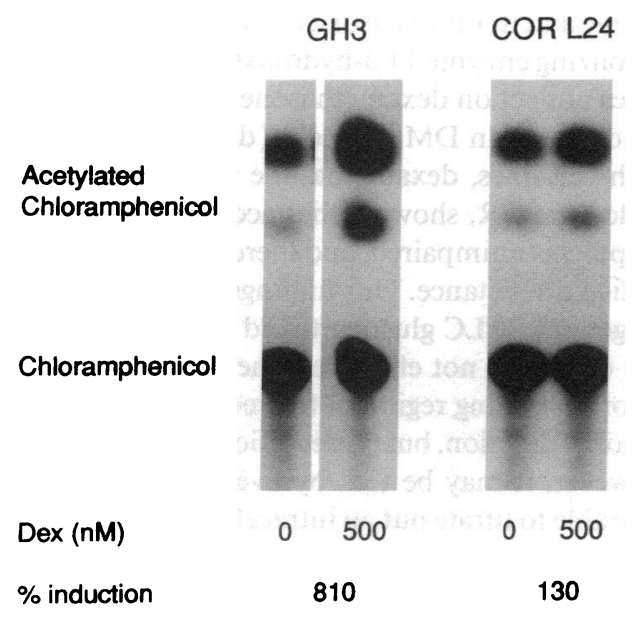

Figure 2. $\mathrm{GH}_{3}$ and COR L24 cells were transfected with the glucocorticoid inducible reporter gene GMCO and then incubated with $500 \mathrm{nM}$ dexamethasone. In $\mathrm{GH}_{3}$ cells, dexamethasone induced CAT expression to $810 \pm 75 \%$ of control $(n=3)$, but in COR L24 cells, the same concentration of dexamethasone induced CAT expression to $130 \pm 17 \%$ of control $(n=3)$.

cells showed no significant induction of CAT expression by $500 \mathrm{nM}$ dexamethasone or 1,000 nM hydrocortisone (Fig. 2), and even concentrations as high as $2,000 \mathrm{nM}$ dexamethasone had no effect ( $104 \pm 13 \%$ of control, $n=3$ ) (Fig. 3 ). The same experiments were extended to two other POMC-expressing SCLC cell lines, COR L103 and DMS 79, but again no induction of transcription from GMCO was observed after dexamethasone treatment, even at 2,000 nM (Fig. 3).

Glucocorticoids act to repress transcription at lower concentrations than those needed for transactivation (14), and this could occur by receptor interaction with other transcription factors, such as AP-1 (15-17). Our original data had indicated that the POMC gene was resistant to suppression by glucocorticoid, and since the mechanism of glucocorticoid action on POMC is complex, we therefore wished to examine inhibition of another negatively regulated reporter gene, (TRE) $)_{3}$ tkCAT. Again, in 11 separate experiments performed in triplicate, this construct transfected in COR L24 cells failed to respond to hydrocortisone ( 500 or $1,000 \mathrm{nM}$ ) or dexamethasone ( 500 or $2,000 \mathrm{nM}$ ), in contrast to the inhibition of CAT expression to $23 \%$ of control levels seen in the $\mathrm{GH}_{3}$ cells $(n=2)$ (Fig. 4). This failure of glucocorticoid-mediated transcriptional repression was seen with both basal and phorbol esterstimulated (TPA at $100 \mathrm{ng} / \mathrm{ml}$ ) transcription from the $(\mathrm{TRE})_{3}$-tkCAT construct. These experiments were repeated in both COR L103 and DMS 79 cells with similar results (data not shown).

To determine whether authentic glucocorticoid receptor could restore glucocorticoid signaling, we expressed a wildtype, human sequence glucocorticoid receptor in the SCLC cells, using the plasmid RS-hGR $\alpha$ and found that it restored glucocorticoid action on both the positive (GMCO) and negative ((TRE) $)_{3}$-tkCAT) reporter genes. In three separate experiments in which RS-hGR $\alpha$ was cotransfected with GMCO into COR L24 cells subsequent incubation with $500 \mathrm{nM}$ hydrocortisone caused $202 \pm 49 \%$ induction of CAT expression, and incubation with $500 \mathrm{nM}$ dexamethasone caused $9,100 \pm 910 \%$ in- duction $(n=3)$. In addition, when (TRE) $)_{3}$-tkCAT was coexpressed, $500 \mathrm{nM}$ dexamethasone suppressed CAT expression to $75 \pm 3 \%$ of control $(n=3)$ (Fig. 5). Furthermore, when dexamethasone concentrations ranging from $1 \mathrm{nM}$ to $500 \mathrm{nM}$ were incubated with COR L24 cells that had been transfected with GMCO plasmid and RS-hGR $\alpha$, there was a significant induction of CAT expression with an $\mathrm{EC}_{50}$ of $\sim 10 \mathrm{nM}$ dexamethasone $(n=3)$ (Fig. 5$)$.

Control experiments using the same Rous sarcoma virus expression vector but with the coding sequence for GR substituted by $\beta$-lactamase cDNA (13) failed to influence activity of the reporter plasmids (data not shown), thereby excluding "squelching" (18) as a possible explanation of these results.

\section{Discussion}

In the present studies, we have addressed the nature of the glucocorticoid resistance of POMC expression in human SCLC cell lines. The POMC gene has a complex promoter that requires the action of both ubiquitous and tissue-specific factors for expression. There are two regions ([-77/-51] [19] and $[-480 /-320][20])$ that appear to allow glucocorticoid repression of gene expression, possibly by disrupting the action of other, as yet unidentified, transcription factors at these elements. Because of this complexity and the detection of high affinity glucocorticoid binding in one severely glucocorticoidresistant cell line, COR L24, we wished to examine the integrity of glucocorticoid signaling in three SCLC cell lines by studying the effects of glucocorticoids on simple, well-characterized reporter genes.

Initial experiments showed that the COR L24 cells contained high affinity binding activity for the specific glucocorticoid receptor ligand, dexamethasone, but high affinity binding could not be consistently detected in DMS 79 cells. The concentration of receptors was consistently less in COR L24 than in the AtT20 control cells, but cell type specific variations in level of receptor expression has been described before (21). The $B_{\max }$ obtained for COR L24 of $11.1 \mathrm{fmol} /$ liter can also be

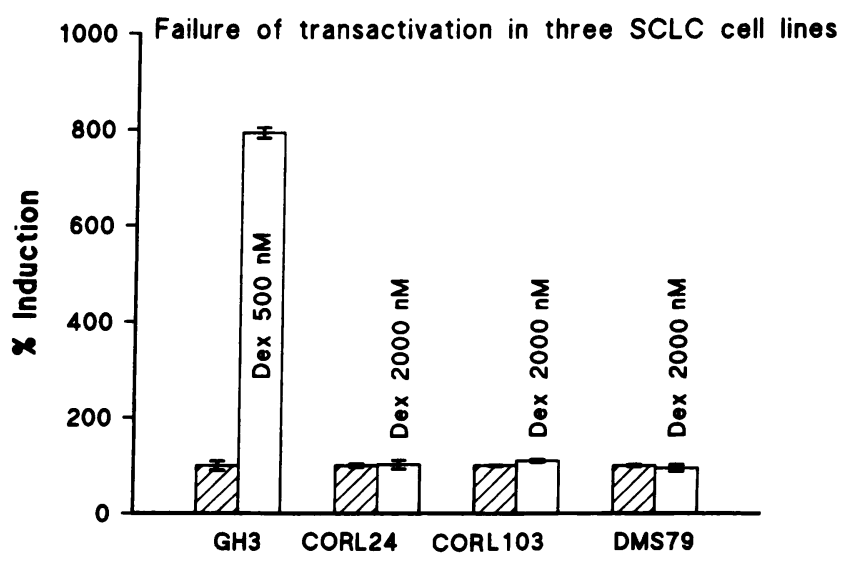

Figure 3. The transfection assay was extended to two other SCLC cell lines that also express the POMC gene. 2,000 nM dexamethasone failed to significantly induce CAT expression from GMCO. Incubations were performed in triplicate and results are presented as the mean \pm SEM and are representative of experiments performed on three occasions. 
GH3
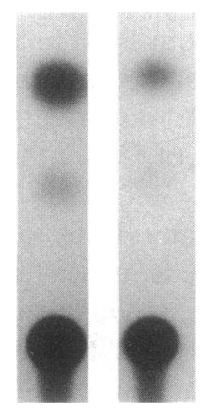

Dex
$(\mathrm{nM})$

$\%$

induction

Figure 4. The dexamethasone-repressible reporter gene (TRE) tkCAT was transfected into $\mathrm{GH}_{3}$ cells and COR L24 cells, which were then incubated with dexamethasone and TPA $(100 \mathrm{ng} / \mathrm{ml})$.

expressed as 6,660 receptors per cell, which accords well with values of 7,191 receptors per cell found in peripheral blood mononuclear leukocytes from healthy volunteers; a glucocorticoid receptor concentration that permitted dexamethasone inhibition of PHA-stimulated $\left[{ }^{3} \mathrm{H}\right]$ thymidine incorporation (22). It was, therefore, felt that the reduced receptor concentration alone was not sufficient to confer global glucocorticoid resistance.

The transfection assays showed a failure of both glucocorticoid-induced transcriptional activation and repression in the SCLC cell lines. The GMCO construct depends on binding of activated glucocorticoid receptor to DNA for transcriptional enhancement, whereas (TRE) ${ }_{3}$-tkCAT is repressed by glucocorticoid receptor binding to the AP-1 transcription factor, and so preventing transcription from its response element (14). Data published after these studies were performed suggests that the inhibition of the POMC gene by glucocorticoids involves binding of three GR molecules to one of the glucocorticoid response elements (23). As yet, the mechanisms of $\mathrm{GR}$ action on POMC transcription have not been fully defined, and so while the (TRE) ${ }_{3}$-tkCAT reporter gene usefully addresses one aspect of GR-mediated repression, it may not represent GR action on the POMC gene. The experiments with GMCO showed a lack of effective glucocorticoid signaling in SCLC cells in response to both the physiological glucocorticoid hydrocortisone and dexamethasone, even at very high concentration. This failure extended to the glucocorticoid repressible reporter (TRE) ${ }_{3}$-tkCAT, confirming significant functional failure of the endogenous glucocorticoid receptor leading to a global defect in glucocorticoid signaling, rather than irreversible inactivation of some endogenous steroid target genes, as has been described in other steroid-resistant models (24). Thus, defective glucocorticoid suppression of the POMC gene is directly explicable by the defect in GR function and does not need to implicate other factors.

The results show restoration of appropriate glucocorticoid signaling to both the reporter genes with wild type GR. The significant difference in potency between the physiological li- gand hydrocortisone and dexamethasone is probably caused by the steroid metabolizing enzyme $11 \beta$-hydroxysteroid dehydrogenase, which does not act on dexamethasone. This difference in potency was not found in DMS 79 cells (data not shown). However, in both cell lines, dexamethasone was an effective ligand for the wild type GR, showing that access of steroid to intracellular receptors is unimpaired, and therefore not the reason for glucocorticoid resistance. Our findings suggest that although the endogenous SCLC glucocorticoid receptor is present in COR L24 cells, it is not effective. One explanation for this is mutation of the coding region of the receptor leading to loss of transcriptional function, but preservation of ligand binding activity. However, it may be that by overexpressing wild type GR, we were able to titrate out an intracellular inhibitor of
A

Plasmid

Acetylated Chloramphenicol

Chloramphenicol \& $\operatorname{Dex}(\mathrm{nM})$

$\%$ induction
COR L24

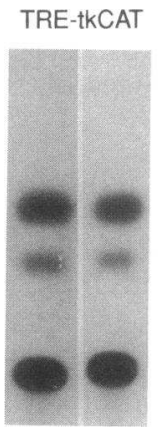
75
GMCO

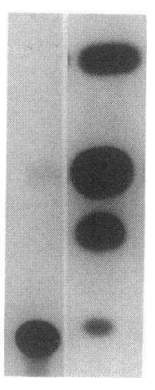

0500

9100

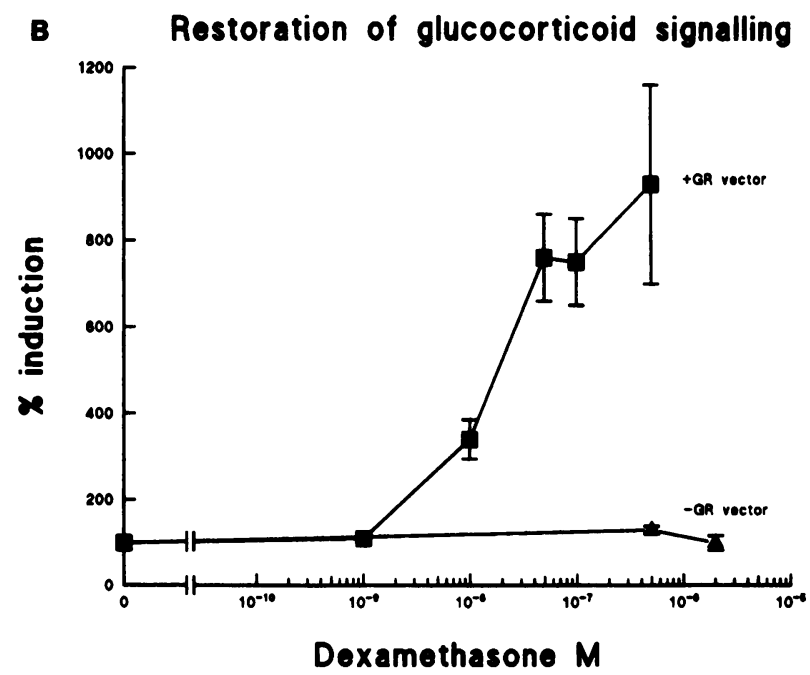

Figure 5. (A) Cotransfection of human GR expression vector RShGR $\alpha$ with both positive (GMCO) and negative ((TRE) $\left.{ }_{3}-t k C A T\right)$ reporter genes into COR L24 cells. The first two lanes show inhibition of TPA-induced CAT expression by $500 \mathrm{nM}$ dexamethasone. The second two lanes show induction of CAT expression from GMCO by $500 \mathrm{nM}$ dexamethasone. $(B)$ Dexamethasone dose response curve comparing induction from GMCO with and without cotransfected RS-hGR $\alpha$. This shows significant induction of GMCO expression at the expected concentration of $10 \mathrm{nM}$ dexamethasone. 
GR action, and by analogy with thyroid hormone resistance (25) or estradiol resistance in breast cancer (26), this could be a dominant negative mutant allele GR. Another candidate inhibitor is the AP-1 transcription factor, since AP-1 and GR can suppress each other's transcriptional activity by interaction at the protein level $(14,16)$. It is conceivable that derangement of AP-1, by either an activating mutation or overexpression, may underlie the glucocorticoid resistant phenotype seen in COR L24.

In the three SCLC cell lines studied, POMC expression has been a "marker" for glucocorticoid resistance, but not all SCLC tumors or cell lines expression POMC. The contribution of glucocorticoid resistance to the ectopic expression of POMC in these SCLC cell lines cannot be determined from this study, but the failure of glucocorticoid regulation of POMC expression stems from defective glucocorticoid signaling, and this may be the case in vivo. This suggests that glucocorticoid resistance may occur in a significant proportion of human SCLC tumors, and such defective signaling has implications for other signaling cascades, such as those terminating with the AP-1 transcription factor, which is known to interact with activated glucocorticoid receptor $(14,16)$.

Glucocorticoid receptors are present in a large number of human solid tumors and in all malignancies of lymphoid origin (27). Important effects of glucocorticoids on tumor growth and differentiation have been described in some cases, but few data exist for lung tumors. Dexamethasone has been shown to retard growth of a glucocorticoid receptor-positive alveolar cell carcinoma (28) and to reduce tumor size in human adenocarcinoma xenografts in nude mice. As Norgaard and Poulsen suggest, extension of these studies to other human malignancies to characterize possible roles for GR is urgently required (27).

Resistance to glucocorticoids also exists as a familial condition, and although rare, it is increasingly being recognized. This is characterized by increased cortisol production without clinical evidence of hypercortisolism, but with manifestations of androgen and mineralocorticoid excess driven by ACTH. This syndrome appears to be caused exclusively by mutations of the glucocorticoid receptor gene, and so far, these are either point mutations in the ligand binding domain $(29,30)$ or loss of allele expression (31). In all the cases described to date, the mutations result in mild resistance to glucocorticoids, which can be overcome by modestly increased glucocorticoid concentrations, in contrast to the severe glucocorticoid resistance found in these studies using three SCLC cell lines.

In conclusion, we have shown a major defect in glucocorticoid signaling in a panel of POMC expressing human SCLC cell lines, which can be corrected by expression of human glucocorticoid receptor. Thus, the reason that POMC transcription is not affected by glucocorticoids is a general failure of the endogenous glucocorticoid receptor. This failure will impact on other aspects of cellular metabolism and division and may have implications for tumor survival. Further studies are underway to determine the precise cause of resistance in this important in vitro model of human malignancy.

\section{Acknowledgments}

D. W. Ray was supported by a Medical Research Council Clinical Training Fellowship.

\section{References}

1. Imura, H., S. Matsukwa, and H. Yamamoto. 1980. Studies of ectopic ACTH-producing tumors. Cancer (Phila.). 35:1430-1435.

2. Liddle, G. W., W. E. Nicholson, D. P. Island, D. N. Orth, D. K. Abe, and S. C. Lowder. 1969. Clinical and laboratory studies of the ectopic humoral syndromes. Recent Prog Horm Res. 25:283-305.

3. Texier P. L., Y. DeKeyzer, R. Lacave, D. Vieau, F. Lenne, A. Rojas-Miranda, J. M. Verley, J.-P. Luton, A. Kahn, and X. Bertagna. 1991. Proopiomelanocortin gene expression in normal and tumoral human lung. J. Clin. Endocrinol. Metab. 73:414-420.

4. Gilby, E. D., L. H. Rees, and P. K. Bondy. 1975. Ectopic hormones as markers of response to therapy in cancer. Excerpta Med. Int. Congr. Ser. 375:132-138.

5. White, A., M. F. Stewart, W. E. Farrell, S. R. Crosby, P. M. Lavender, P. R. Twentyman, L. H. Rees, and A. J. L. Clark. 1989. Proopiomelanocortin gene expression and peptide secretion in human small cell lung cancer cell lines. $J$. Mol. Endocrinol. 3:65-70.

6. Clark, A. J. L., M. F. Stewart, P. M. Lavender, W. E. Farrell, S. R. Crosby, L. H. Rees, and A. White. 1990. Defective glucocorticoid regulation of proopiomelanocortin gene expression and peptide secretion in a small cell lung cancer cell line. J. Clin. Endocrinol. Metab. 70:485-490.

7. Farrell, W. E., M. F. Stewart, A. J. L. Clark, S. R. Crosby, J. R. E. Davis, and A. White. 1993. Glucocorticoid inhibition of ACTH peptides: small cell lung cancer cell lines are more resistant than pituitary corticotroph adenoma cells. $J$. Mol. Endocrinol. 10:25-32.

8. Hoggard, N. J. R. E. Davis, M. Berwaer, P. Monget, B. Peers, A. Belayew and J. Martial. 1991. Pit-1 binding sequences permit calcium regulation of human prolactin gene expression. Mol. Endocrinol. 5:1748-1752.

9. Godowski, P. J., D. Picard, K. R. Yamamoto. 1988. Signal transduction and transcriptional regulation by glucocorticoid receptor-Lex $\mathrm{A}$ fusion proteins. Science (Wash. DC). 241:812-816.

10. Angel, P., M. Imagawa, R. Chiu, B. Stein, R. J. Imbra, H. J. Rahmsdorf, C. Jonat, P. Herrlich, and M. Karin. 1987. Phorbol ester-inducible genes contain a common element recognised by a TPA-modulated trans-acting factor. Cell. 49:729-739.

11. Luckow, B., and G. Schutz. 1987. CAT constructions with multiple unique restriction sites for the functional anlaysis of eukaryotic promoters and regulatory elements. Nucleic Acids Res. 15:5490.

12. Giguere, V., S. M. Hollenberg, M. G. Rosenfeld, and R. M. Evans. 1986. Functional domains of the human glucocorticoid receptor. Cell. 46:645-652.

13. Gorman, C., L. F. Moffat, and B. H. Howard. 1982. Recombinant genomes which express chloramphenicol acetyl transferase in mammalian cells. Mol. Cell. Biol. 2:1044-1051.

14. Jonat, C., H. J. Rahmsdorf, K.-K. Park, A. C. B. Cato, S. Bebel, H. Ponta, and P. Herrlich. 1990. Antitumour promotion and antiinflammation: down-modulation of AP-1 (fos/jun) activity by glucocorticoid hormone. Cell. 62:11891204.

15. Diamond, M. I., J. N. Miner, S. K. Yoshinaga, and K. R. Yamamoto. 1990. Transcription factor interactions: selectors of positive or negative regulation from a single DNA element. Science (Wash. DC). 249:1266-1272.

16. Yang-Yen, H.-F., J.-C. Chambard, Y.-L. Sun, T. Smeal, T. J. Schmidt, J. Drouin, and M. Karin. 1990. Transcriptional interference between c-jun and the glucocorticoid receptor: mutual inhibition of DNA binding due to direct proteinprotein interaction. Cell. 62:1205-1215.

17. Chatterjee, V. K. K., L. D. Madison, S. Mayo, and J. L. Jameson. 1991. Repression of the human glycoprotein hormone $\alpha$-subunit gene by glucocorticoids: evidence for receptor interactions with limiting transcriptional activators. Mol. Endocrinol. 5:100-110.

18. Ptashne, M. 1988. How eukaryotic transcriptional activators work. Nature (Lond.). 335:683-689.

19. Drouin, J., M. A. Trefiro, R. K. Plante, M. Nemer, P. Eriksson, and O. Wrange. 1989. Glucocorticoid receptor binding to a specific DNA sequence is required for hormone-dependent repression of proopiomelanocortin gene transcription. Mol. Cell Biol. 9:5305-5314.

20. Riegel, A. T., Y. Lu, J. Remenick, R. G. Wolford, D. S. Berard, and G. L. Hager. 1991. Proopiomelanocortin gene promoter elements required for constitutive and glucocorticoid-repressed transcription. Mol. Endocrinol. 5:1973-1982.

21. Kalinyak, J. E., C. A. Griffin, R. W. Hamilton, J. G. Bradshaw, A. J. Perlman, and A. R. Hoffman. 1989. Developmental and hormonal regulation of glucocorticoid receptor messenger RNA in the rat. J. Clin. Invest. 84:1843-1848.

22. Lamberts, S. W. J., J. W. Koper, P. Biemond, F. H. Den Holder, and F. H. De Jong. ( 1992) Cortisol receptor resistance: the variability of its clinical presentation and response to treatment. J. Clin. Endocrinol. Metab. 74:313-321.

23. Drouin, J., Y. L. Sun, M. Chamberland, Y. Gauthier, A. DeLean, M. Nemer, and T. J. Schmidt. 1993. Novel glucocorticoid receptor complex with DNA element of the hormone-repressed POMC gene. EMBO (Eur. Mol. Biol. Organ.) J. 12:145-156. 
24. Darbre, P. D., and R. J. B. King. 1987. Progression to steroid insensitivity can occur irrespective of the presence of functional steroid receptors. Cell. 51:521-528.

25. Meier, C. A., B. M. Dickstein, K. Ashizawa, J. H. McClaskey, P. Muchmore, S. C. Ransom, J. B. Menke, E.-H. Hao, S. J. Usala, B. B. Bercu, S.-Y. Cheng, and B. D. Weintraub. 1992. Variable transcriptional activity and ligand binding of mutant $\beta$ 13,5,3'-triiodothyronine receptors from four families with generalized resistance to thyroid hormone. Mol. Endocrinol. 6:248-258.

26. Wang, Y., and R. J. Miksicek. 1991. Identification of a dominant negative form of the human estrogen receptor. Mol. Endocrinol. 5:1707-1716.

27. Norgaard, P., and H. S. Poulsen. 1991. Glucocorticoid receptors in human malignancies: A review. Ann. Oncol. 2:541-557.

28. Jones, K. L., N. S. Anderson III, and J. Addison. 1978. Glucocorticoid induced growth inhibition of cells from a human lung alveolar cell carcinoma. Cancer Res. 38:1688-1693.

29. Hurley, D. M., D. Accili, C. Stratakis, M. Karl, N. Vamvakopoulos, K. Rorer, K. Constantine, S. I. Taylor, and G. P. Chrousos. 1991. Mutation of the human glucocorticoid receptor in familial glucocorticoid resistance. J. Clin. Invest. 87:680-686.

30. Malchoff, D. M., A. Brufsky, G. Reardon, P. McDermott, E. C. Javier, C.-H. Bergh, D. Rowe, and C. D. Malchoff. 1993. A mutation of the glucocorticoid receptor in primary cortisol resistance. J. Clin. Invest. 91:1918-1925.

31. Karl, M., S. W. J. Lamberts, S. D. Detera-Wadleigh, I. J. Encio, C. A. Stratakis, D. M. Hurley, D. Accili, and G. P. Chrousos. 1993. Familial glucocorticoid resistance caused by a splice site deletion in the human glucocorticoid receptor gene. J. Clin. Endocrinol. Metab. 76:683-689. 